\title{
Designing Interaction for Local Communications: An Urban Screen Study
}

\author{
Fiona Redhead and Margot Brereton \\ Queensland University of Technology, Australasian CRC for Interaction Design, \\ Queensland, Australia \\ f.redheadastudent.qut.edu.au, m.brereton@qut.edu.au
}

\begin{abstract}
This paper discusses the ongoing design and use of a digital community noticeboard situated in a suburban hub. The design intention is to engage residents, collect and display local information and communications, and spark discussion. A key contribution is an understanding of Situated Display navigation that aids retrieval from a long-term collection created by and for suburban community, and engaging qualities of this collection.
\end{abstract}

Keywords: Situated Display, Internet Technologies, Interaction, Urban Screen.

\section{Introduction}

This paper presents formative evaluation of a long-term study of a digital community noticeboard (figure 1) located in a general store in an outer suburb of Brisbane, Australia (figure 2). Other evaluations of publicly accessible Situated Displays have focused on observing interaction with either predetermined content or particular media [1-4] and present limited exploration of how the engaging qualities of Situated Displays can be applied to build a mesh of grassroots and sustainable communications focused around the display locality. This research is evolving over time in a local community context and through use [5], and aims to evaluate capacity for Situated Displays to support diverse local urban communications. The noticeboard is a starting point and visible focus of our efforts to find better ways to facilitate local communication and build cohesion in a suburb that is in some respects a "dormitory" or commuter suburb. Our prior research observed the difficulty residents of such suburbs face in communicating with each other around issues of importance and identified the desire for greater community interaction [6].

A key data feed into the design process is the participation of our users, which has been increasing with time. Our focus is to grow participation in order to increase the capacity for and habit of community communication. The strategy for growth is to make the noticeboard as useful, useable and engaging as possible. We understand from beta development some needs people have in regard to interacting with a Situated Display in a local urban context, and we plan to continue this relationship with our participants through supporting and inviting further participation. Decreasing barriers to participation and discovering interactions that engage people and mesh with their everyday experiences is key to growing the capacity for use. 


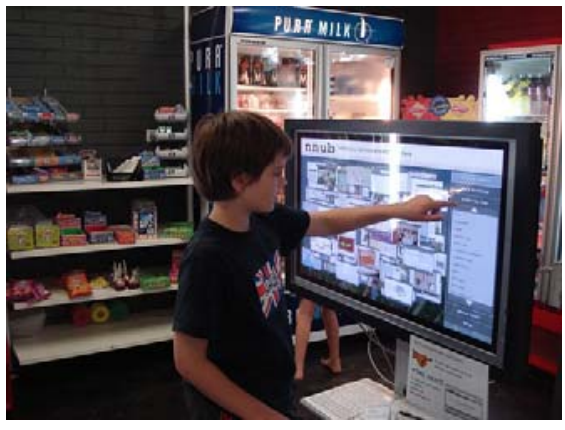

Fig. 1. The noticeboard in use

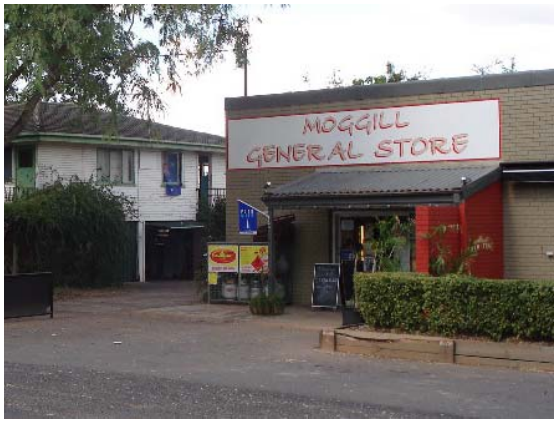

Fig. 2. The general store

The noticeboard is situated in a local general store to allow rapid perusal of community content in a place that is passed by many local people frequently. The store is located opposite a primary school creating a community hub that people use for everyday interactions, both casual and more structured (i.e. fundraising activity).

The name of the noticeboard is 'Nnub' (an abbreviation of neighbourhood nub). Nnub is the coupling of a Situated Display and Internet technologies and operates through a Situated Display (noticeboard) interface on a touch enabled 40" panel and a Web interface. While the interfaces hold the same content for viewing, they are designed to serve different purposes. The noticeboard interface is directed at engaging people, browsing, and quick notice creation and distribution using the touch display and mobile devices (mobile interaction is planned for future iterations). The Web interface is directed at follow up interaction, searching, and creation and distribution of notices using files typically stored on a home computer. A desktop computer is installed at the shop to provide Web interface access. Anyone can post to Nnub.

\section{Design and Use}

As argued in the Community Informatics literature, grassroots engagement is required to create and sustain effective technologies for community building activity [7]. However participation in community building activity that is not conceived from grassroots motivation requires some level of invitation either through direct invitation or exposure $[8,9]$. This research applies an exploratory prototype as a means to invite participation and inspire design iterations. The exploratory prototype is a central artefact in the Reflective Agile Iterative Design (RAID) framework [10, 11].

RAID is a framework for evolving social software through reflective and timely response, by the practitioner, to use. The primary contributing framework is Action Research. RAID is a cyclic process of design, feedback, and reflection focused around the development of an exploratory prototype. The RAID framework is applicable to our research as we evolve the design in a dialogue with how people use the interface and in a time frame that indicates the process is active and responsive.

Although Situated Displays have potential to engage people, barriers to participation can hinder this potential [12]. To move people to direct interaction, Brignull and Rogers [12] suggest the interface should clearly convey low commitment interaction 
that is quick and enjoyable. Brignull and Rogers made this observation at a single event. Our challenge is to decrease barriers to interaction (through both the noticeboard and associated Web interface) in order to grow participation and the capacity to support community communication in the long-term.

Our process involves iteratively changing our design in response to use, while also extending the functionality to seek further feedback with the aim of discovering interactions that are in varying degrees quick and enjoyable, yet serve to collect and support local communications. We have observed that people prefer to interact with the notices as objects on the noticeboard rather than through text based navigation, and prefer to interact with image notices rather than text focused notices. These observations led us to improve the interface and discover other means of engaging people in creating noticeboard content of interest to the community. Logging statistics reported below were collected from June 2008 to January 2009.

The navigation for an initial noticeboard layout was used very little, with people by far preferring to directly touch a notice in view (to look at in full size) than to use the primary or secondary navigation. Primary level navigation was conducted through the top menu bar (category, author, title, date) and side panel (photos or notices) and accounted for $13 \%$ of total touches. Secondary level navigation, which selected among categories, accounted for $6 \%$ of total touches. Similar findings have been observed on a Situated Display designed to display local photos at Wray Village [1]. Logging data and observations indicated people did not pay attention to navigation buttons and interacted directly with images in view.

However building a collection of information and communications for long-term reference requires useful navigation. This led us to implement open tagging. Rather than assigning prescribed categories, tags are added by the community of Nnub users (as contributors) to describe the growing body of content. In addition we removed all other forms of navigation leaving tags as the means to find particular notices. Of the total touches, touching a tag to view notices tagged with that word accounts for $30 \%$. This indicates that open tagging is more meaningful to the community than the previous generic metadata and categories we had specified.

Related to this tendency to interact directly with the notices rather than text based navigation is the difference in habit of what people like to view and what they post. Viewing image notices (no text) at full size accounts for $44.9 \%$ (of the total touches including navigation) while viewing text focused notices at full size accounts for $7.9 \%$ (of the total touches including navigation). However, only $10 \%$ of uploads from registered users are image notices while $43 \%$ are text focused notices.

Based on these observations we have evolved the noticeboard as an exploratory prototype to increase direct interaction with images on the Situated Display. We have implemented 'Scribbles' [2]. Scribbles are created by drawing or writing directly on the touch screen and have been extremely popular with children and have rapidly increased the visuals on the noticeboard. This growth of Scribbles brings new considerations for interface design both in terms of extending possibilities around successful engagement, and preserving the core design intentions. Through Flickr we invited 16 people to join a group created around the locality of Nnub. The images added to the group are fed to Nnub. Of the 16 people invited, 10 people added images. This use of other Web 2.0 interfaces to grow participation extends our reach to find relevant content. We plan to publicise statistics about use to the users to allow reflective use 
$[10,11]$. This will illustrate the popularity of image notices and may increase the creation of image and image focused notices.

A key contribution of this work is the design and long term community deployment of an instrumented noticeboard that has enabled us to understand barriers to interaction with a Situated Display in a local urban context, in addition to exploring possibilities for creating content that people like to engage with. Future work will continue to respond to use to evolve solutions that reflect the range of information and communications that shape the local suburb.

Acknowledgements. This research/work was partly conducted within the Australasian CRC for Interaction Design, which is established and supported under the Australian Government's Cooperative Research Centres Programme. We would like to thank the general store for their generosity and enthusiasm.

\section{References}

1. Taylor, N., Cheverst, K., Fitton, D., Race, N., Rouncefield, M., Graham, C.: Probing Communities: Study of a Village Photo Display. In: OZCHI 2007, pp. 17-24. ACM, New York (2007)

2. Churchill, E., Nelson, L.: Interactive Community Bulletin Boards as Conversational Hubs and Sites for Playful Visual Repartee. In: HICSS-40 2007, pp. 76-85. IEEE Press, New York (2007)

3. Peltonen, P., Salovaara, A., Jacucci, G., Ilmonen, T., Ardito, C., Saarikko, P., Batra, V.: Extending Large-Scale Event Participation with User-Created Mobile Media on a Public Display. In: MUM 2007, pp. 131-138. ACM, New York (2007)

4. Peltonen, P., Kurvinen, E., Salovaara, A., Jacucci, G., Ilmonen, T., Evans, J., Oulasvirta, A., Saarikko, P.: "It's Mine, Don't Touch!": Interactions at a Large Multi-Touch Display in a City Centre. In: CHI 2008, pp. 1285-1294. ACM, New York (2008)

5. Brereton, M.: Designing from Somewhere: A located, relational and transformative view of design. In: Löwgren, J., Malmborg, L., Binder, T. (eds.) (Re-) searching a digital Bauhaus, pp. 99-119. Springer, London (2009)

6. Redhead, F., Brereton, M.: A Qualitative Analysis of Local Community Communications. In: OZCHI 2006, pp. 361-364. ACM, New York (2006)

7. Gurstein, M.: Effective Use: A Community informatics strategy beyond the Digital Divide. First Monday 8 (2003)

8. Schuler, D.: The Seattle Community Network: Anomaly or Replicable Model? In: van den Besselaar, P., Koizumi, S. (eds.) Digital Cities III, pp. 17-42. Springer, Heidelberg (2005)

9. Carroll, J.M.: The Blacksburg Electronic Village: A Study in Community Computing. In: van den Besselaar, P., Koizumi, S. (eds.) Digital Cities III, pp. 43-65. Springer, Heidelberg (2005)

10. Heyer, C., Brereton, M.: Reflective Agile Iterative Design. In: SIMTech Workshop on Social Interaction with Mundane Technologies (November 2008)

11. Heyer, C., Brereton, M., Viller, S.: Cross-channel mobile social software: an empirical study. In: CHI 2008, pp. 1525-1534. ACM Press, New York (2008)

12. Brignull, H., Rogers, Y.: Enticing People to Interact with Large Public Displays in Public Spaces. In: INTERACT 2003, pp. 17-24. IOS Press, Amsterdam (2003) 